\title{
Mass Valuation and the Implementation Necessity of GIS (Geographic Information System) in Albania
}

\author{
Elfrida Shehu ${ }^{1}$, Elda Maci Vorpsi ${ }^{2}$ and Alma Afezolli ${ }^{1}$ \\ 1. Civil Engineering Faculty, Polytechnic University of Tirana, Tirana 1001, Albania \\ 2. Municipality of Tirana, Tirana 1001, Albania
}

\begin{abstract}
In the last decade, mass valuation system is applied in Albania in addition to individual valuation system for real estate valuation. This system is used for compiling the land value map and apartments value map. Due to the lack of experience in the compilation of these maps, the methodology of valuation is based on the experiences of other countries with similar development of real estate market. The mass assessment, which is applied in determining the values for specific purposes, such as expropriation, compensation and taxes for property transfer through the methodology adopted for this aim, is analyzed in the light of the finding of issues that accompany this application. The aim of this research is to highlight the problems to provide the ways of overcoming them in order to approximate the values of map values with market values. The mass appraisal process requires effective valuation models and proper management of resources. Its accuracy depends upon the extent and quality of property data available. Because of this reason, it is recommended the usage of the GIS (geographic information system), an automated system for collection and processing of the data necessary for valuation, as the first point of integration between two process of valuation, individual and mass valuation.
\end{abstract}

Key words: Real estate, mass valuation, GIS, map value.

\section{Introduction}

Real estate is one of the most valuable assets all over the world; which is also the case for Albania, individuals, as well as the government. Albania entered on the path of market economy in the early 1990s. The return of real estate to a marketable commodity was a novelty of this period, which was born and was developed along with the need for evaluations.

The purposes, for which the valuation of real estate is required, are diverse. The main basis of evaluation of real estate is the market value. The two main systems for determining market value, used even in Albania, are individual and mass valuation.

This paper attempts to analyze the use of mass appraisal system in Albania with the aim of getting the possible ways to improve the results come from the use of this system.

Corresponding author: Elfrida Shehu, lecturer, research field: real estate valuation. E-mail:elfridaal@yahoo.com.

\section{Main Aspects of the Mass Appraisal System in Albania}

\subsection{Individual and Mass Appraisal System}

The properties are heterogeneous in types, sizes, usability, etc. The purposes, for which valuation of a real estate is required, are diverse, but regardless the purpose of valuation, the most required kind of value and the main basis of evaluation of real estate are the market value. In Albania, individual valuation is widely used for such purposes, like sale, purchase, mortgage, financial reports, property division, developments and redevelopments, etc. Mass valuation is used in compiling maps of values. The maps of values are used for purposes of expropriation, compensation and taxes for property transfer.

\subsubsection{Individual Valuation}

Individual valuation is the valuation of a particular property as of a given date. In case of individual valuation, one or some of real property objects are assessed; Consequently, such valuation is 
distinguished for a detailed analysis and description of the subject property, detailed interpretation of legal and economic factors of value [1].

There are five conventional methods for the assessment of the real estate depending on their type and the purpose of valuation: (1) the comparison method; (2) the investment method; (3) the profit method; (4) the residual method (development method); (5) the cost method. According to International and European Standards, all methods ultimately converge on three methods: method of comparison, the method of investment and cost method [2, 3].

\subsubsection{Mass Valuation}

Mass valuation is the process of valuing a group of properties as of a given date, using common data, employing standardized methods and conducting statistical tests to ensure uniformity and equity in the valuations. Valuation models developed for mass appraisal purposes must represent supply and demand patterns for groups of properties rather than a single property [4]. It is difficult to highlight each of their qualities when they are assessed a large amount of property, so special attention is paid to defining what is common to all properties being valued, but not to the specific features.

The International Association of Assessing Officers and the Appraisal Institute of Canada recognize the applicability of all three approaches to value for use in mass appraisal, cost approach, sales comparison approach and income capitalization approach.

\subsection{Current Methodology of Compiling Map Values for Land and Buildings}

As mentioned above, mass valuation system is used in Albania for compiling the map of values for land and apartments. The methodology for determining the value is approved by Council of Ministers Decision No. 658, dated September 26, 2012 [5].

The calculation of the value of the property is done according to international standards of real estate evaluation, type of property and its intended use. The value of the property is equal to the price of the contract of sale, and the price of sale contracts is defined as the market price. Market price data are provided from official sales contracts registered at the Registry of Real Property. The minimum number of property sales contracts to a cadastral area, subdivision or their union for each type of property, together with the relevant subdivisions, is 3 . But if in a cadastral area, either subdivision or union, there is a lack of sales transactions for a division or subdivision of the type of real estate, the value determination of these areas shall be based on the indirect method, grouping sales contracts at a level close, in this order: municipality (division of municipality), commune (division of commune) and village.

The value of property (group of properties) is determined by statistically processed data collected by the above methodology.

Based on this methodology, there have been developed the maps of land values for cities and villages of Albania.

The maps of values are developed by dividing the territory into values zones. A value zone is an area which has a similar value level and value formation mechanism. Evaluation of land is done based on the principle that active operation and operation with high efficiency of data collection unit of market prices and ensuring a sufficient number of data for analysis, constitute the sole basis to ensure high quality and accuracy of the results provided by the process of evaluating properties [5].

\subsubsection{Map Value of Land}

Fig. 1 represents the map of land values for Tirana City. The value zones are cadastral zones. Tirana is divided in 25 cadastral zones.

The sales comparison approach is the most preferred method of land valuation and probably the only widely-used mass valuation method in the context of land.

This method is based on a direct comparison of 


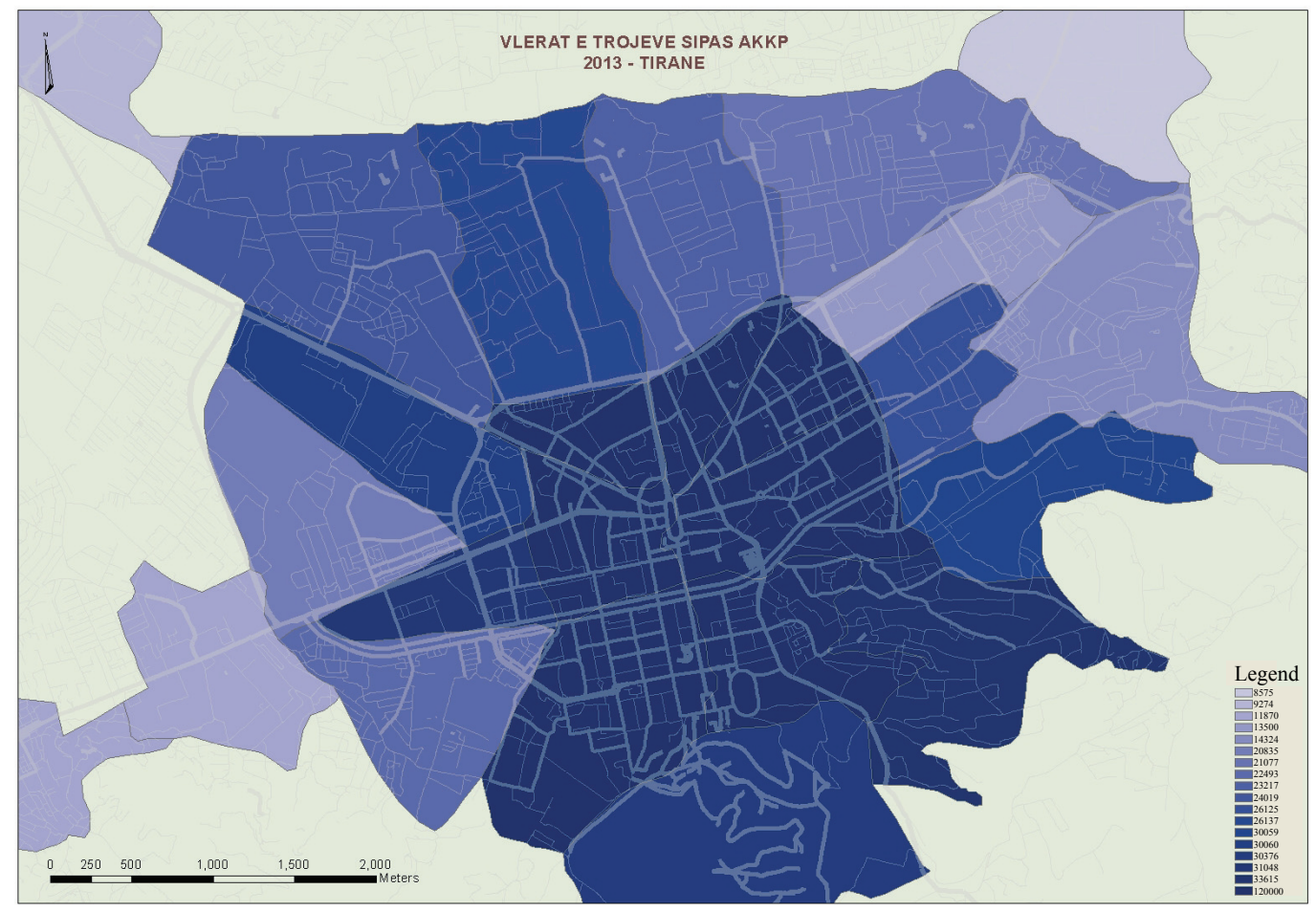

Fig. 1 Map of land values for Tirana City.

market transactions of vacant land, so data from the Immovable Property Registration Offices have to be used [5].

\subsubsection{Map Value of Housing Market (Apartments)}

Tirana, the largest city in Albania $\left(41.8 \mathrm{~km}^{2}\right)$, is divided in 33 zones; while the other cities are divided into a small number of zones. Fig. 2 represents the map of housing (apartments) values for Tirana City. There was no specific reason for this division.

Although the current methodology for assessing properties in Albania Republic includes land and buildings, for housing market, there does not exist a precise methodology. The determination of the reference price in the housing market is made by the guidance for the approval of the average cost of housing construction, as well as average market values for apartments on open market housing, with the proposal of Ministry of Urban Development and Tourism. The last one is approved on August 2014 [6].

The sales comparison approach is the main method of valuation for residential properties. This method entails making a valuation by directly comparing the property under consideration with similar properties which have been sold in the past, using the evidence of those transactions to assess the value of the property under consideration [7].

\section{Data as a Main Element of Mass Appraisal System}

Comparison approach is based on comparability, and accuracy in its use depends on the accuracy and quality of collected data. The process of data collection is complex, which takes times and is costly. Mass appraisal techniques depend upon the extent and quality of property data available. This information is quantitative (e.g., land areas, dimensions, building types, accommodation and fittings) or qualitative (e.g., assessment of physical condition, character or market desirability of structural improvements and classification of submarket groupings) [8].

The qualities of the data, on which the calculation of the value is based, under the current methodology in Albania are the type of property, location, size, date 


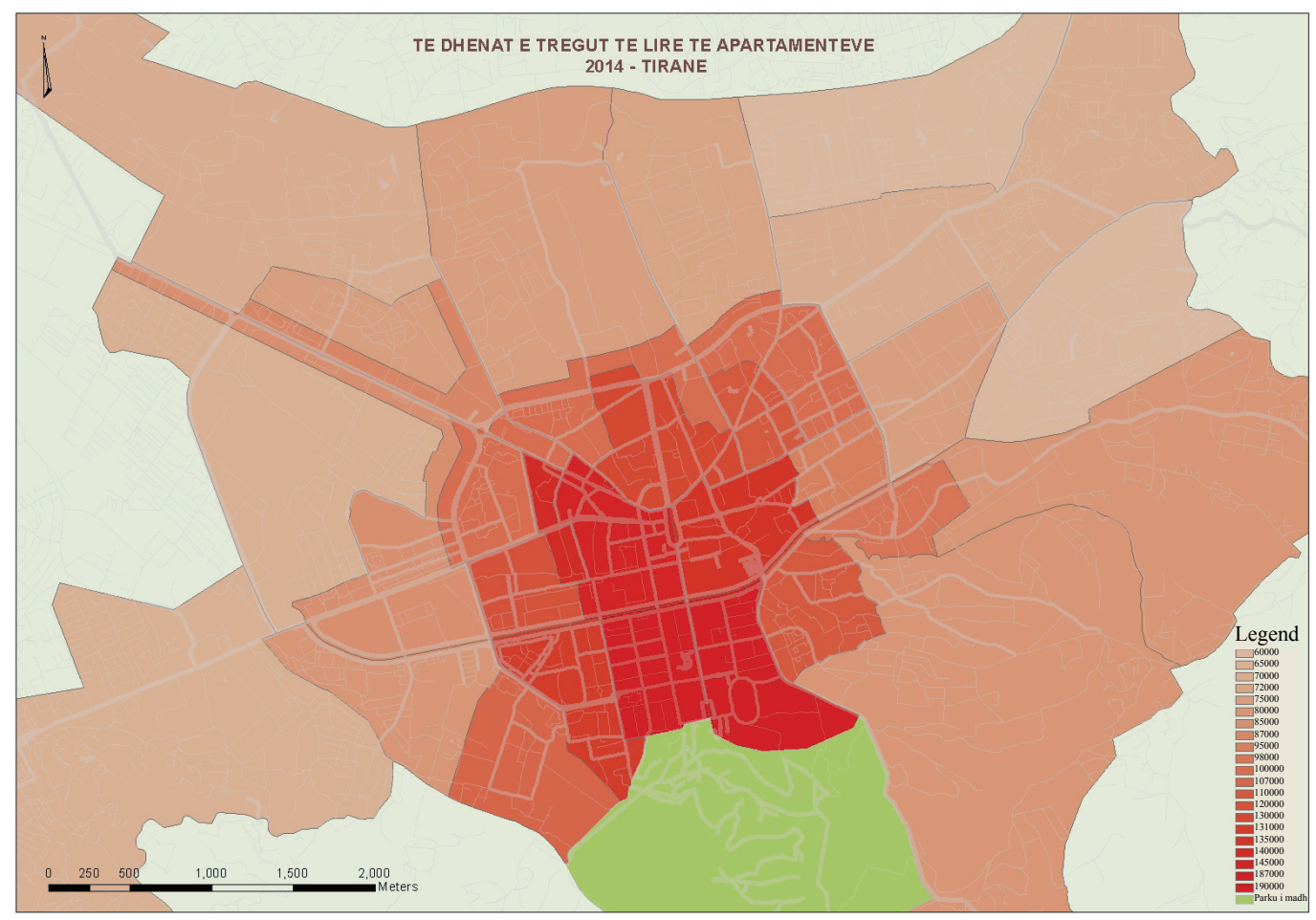

Fig. 2 Map of apartment values for Tirana City.

of the contracts and the price realized in transaction. Many other characteristic of properties, such as proximity to roads, the configuration of surface, construction intensity, etc., are left out of focus.

Mass appraisal requires complete and accurate data, effective valuation models and proper management of resources [9]. The data collected are processed in a statistical way under Annex 1, Article 6 of the Decision in Ref. [5].

\section{Issues of Mass Valuation Application}

The analysis of the current methodology for assessing properties in Albania Republic, as the only application of mass valuation, leads to some issues:

- The same methodology is used as for agricultural land, as well as for land for construction; For housing market, there does not exist a precise methodology. In determining process, the land value is overlooked the principle of usability of the property-one of the determinants of value. According to the regulatory plan of Tirana, the intensity of the construction, which shows the land "productivity", is different in different areas, even within the same cadastral area. Fig. 3 represents the construction intensity for Tirana City. Fig. 4 shows the construction intensity within cadastral zones. As can be seen within a cadastral zone represented by only one value, different pieces of lands have different construction intensities. So in Cadastral Zone 8160, it varies from 1.1 to 4.2 (Fig. 5), in Cadastral Zone 8130 it varies from 0.95 to 2.8 (Fig. 6);

- It has a big value variation from one value zone to another, even in the areas positioned next to each other (Figs. 1 and 2);

- There is a lack of data derived from transactions in the market. The contract prices are often not accurate, while even a part of transaction prices are values from the map of values itself. The market data for urban lands within cities are very limited because of lack transaction for selling and purchase. The land owners increasingly prefer to negotiate with developers in order to benefit part of the construction 


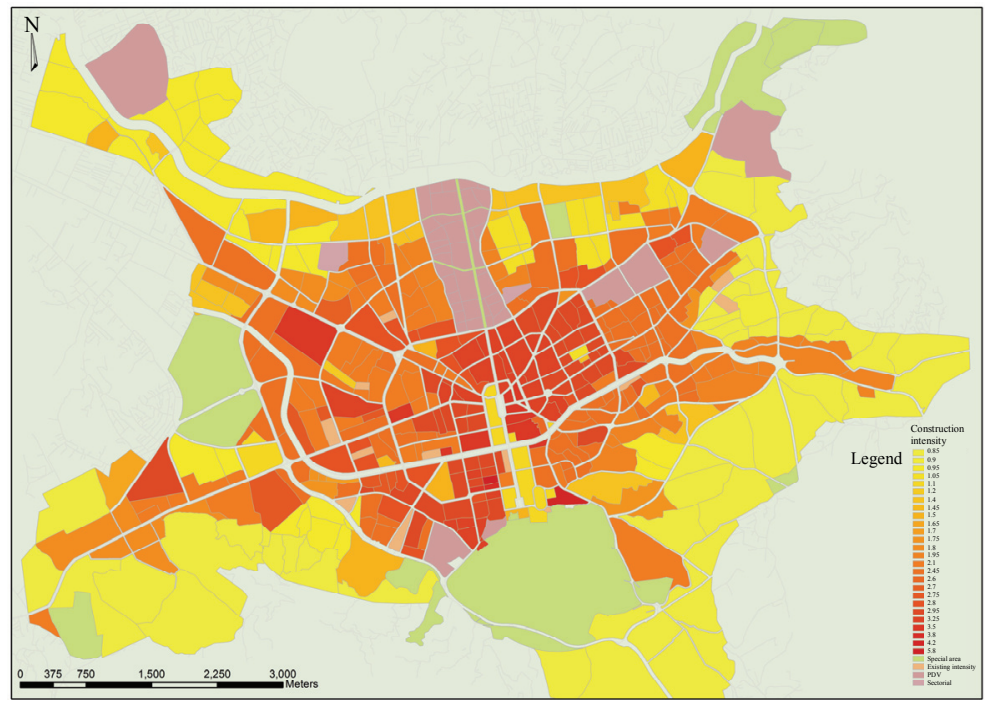

Fig. 3 Construction intensity for Tirana City.

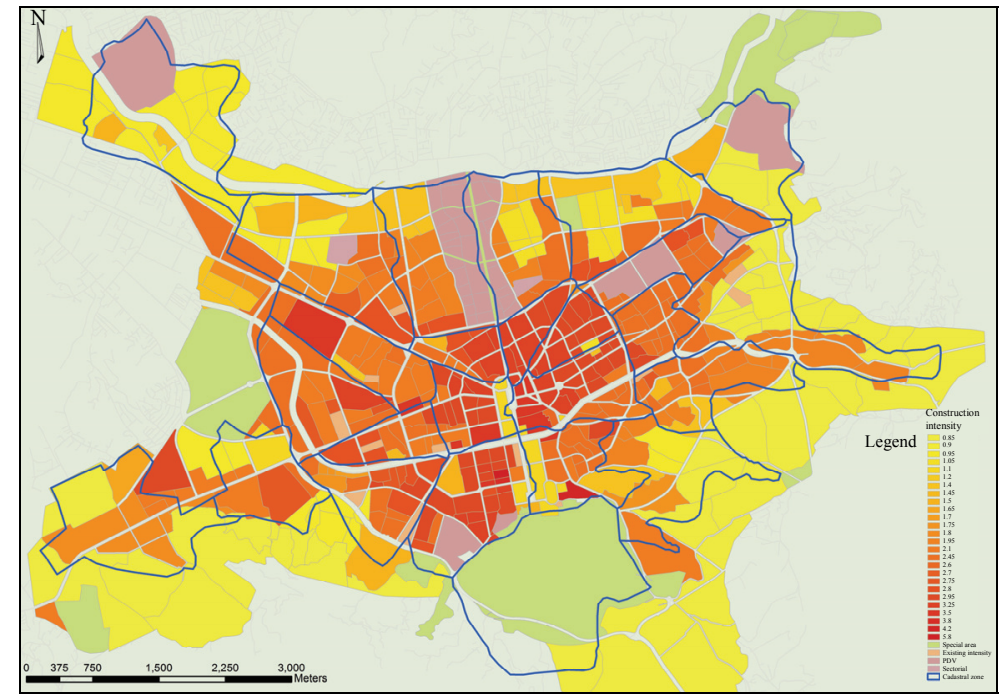

Fig. 4 Construction intensity according to cadastral zones.

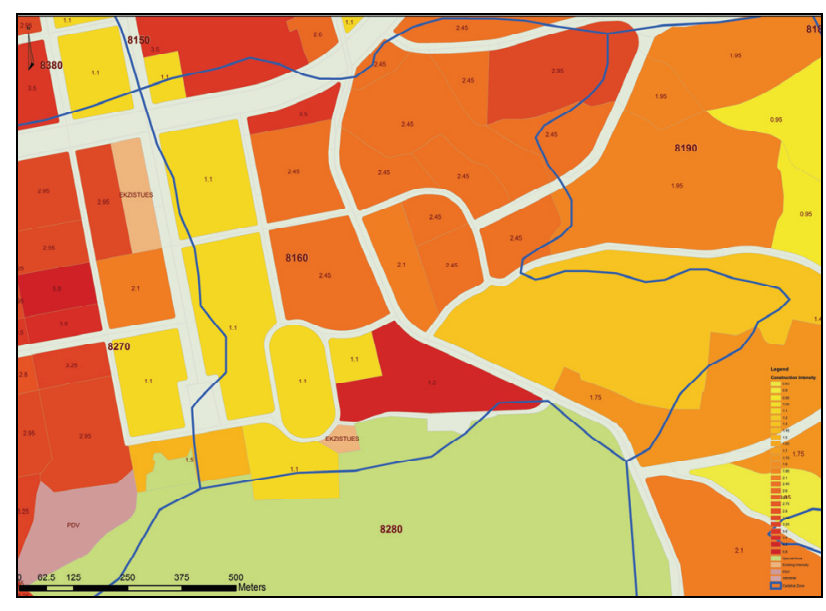

Fig. 5 Construction intensity Cadastral Zone 8160.

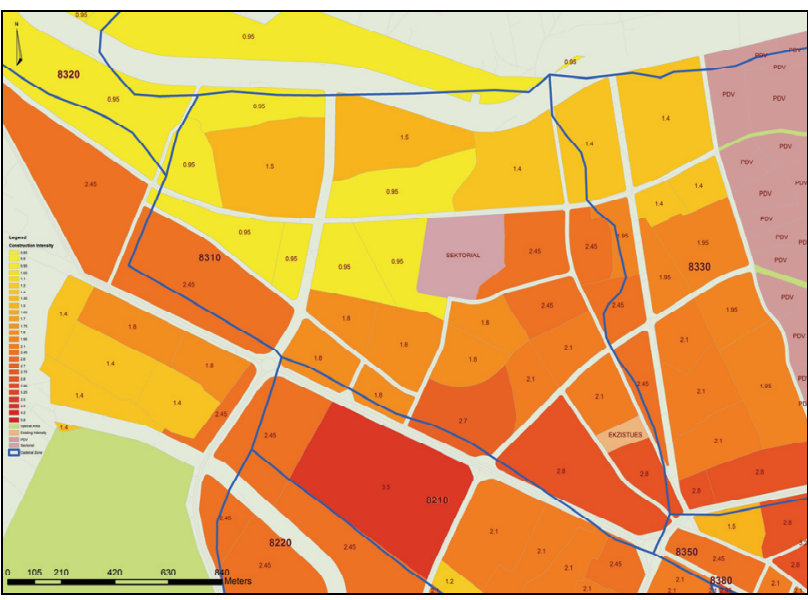

Fig. 6 Construction intensity Cadastral Zone 8130. 
more than to sell the land. The market data for land in rural areas suffer the lack of comparability base. It has market data for housing market, but not officially ones;

- The mass appraisal process must ensure that standards of appraisal level and uniformity are observed in the interests of assessment equity [8]. The appraisal level is the overall ratio of values to market values. In mass valuation, the results cannot be expected to equal the market values of individual properties, but high and low ratios should be balanced. The international documents suggest that the allowable difference between the results of individual and mass valuation should not exceed $20 \%$ [10]. There are significant and non-negligible changes in the values defined using the individual valuation system and the values from map of land values, drawn by mass appraisal system [11].

Uniformity requires equity within group and between groups of properties [1]. Uniformity relates with the equitable treatment of every individual property. Cadastral areas have a very large spatial extent and, therefore, the use of data obtained from sales contracts has need of a processing prior to use [11].

\section{GIS and Its Implementation in Real Estate Valuation}

GIS (geographic information system) is a set of computerized tools (including both hardware and software) for collecting, storing, retrieving, transforming and displaying spatial data.

Mass valuation system is more and more based on digital data. Computerized methodology has made the mass appraisal process more efficient and more widespread. The first and most important point of integration, between two process of valuation, individual and mass valuation, is the development and use of automated system for collection and processing of the data necessary for valuation [10]. Data collected in a uniform digital format are the basic factor of success in developing an automated mass valuation model based on statistical methods.

GIS software and data can be very useful in identifying appropriate comps. An appraiser can display a map showing all recent sales. The appraiser can then "click on" each sold property to show its attributes, to determine whether the property is sufficiently similar, as well as spatially close enough to the subject to be a reliable comp. The appraiser might select different buildings and calculate new valuation scenarios. Once the best comps have been chosen and the valuation has been completed, the appraiser can readily produce a hardcopy map showing the location of the comps and subject, attributes of the properties, neighborhood characteristics (such as census data), etc., to append to the final appraisal document [12].

Incomplete or obsolete property data in the registers are the main obstacle for accurate valuation performance or the introduction of improvements in mass valuation models. The three basic functions of a mass valuation system are revaluation, data maintenance and value updates [13].

\section{Conclusions and Recommendations}

Mass appraisal has been implemented relatively late in Albania, and it should be said that the efforts are still needed for improvement. The method of comparison, baseline for mass valuation, is based on comparability and similarity. Due to the lack of data, the level of accuracy is poor. GIS helps in inclusion of more characteristics of property in the valuation process. This would affect in excluding those data that are not related to the similarity and also would help to narrow the differences between the results come from individual and mass valuation. Actually, GIS implementation is a necessity.

Valuation is the art of determining the value and not simply a mathematical calculation process. The current methodology of valuation creates the impression that you have to follow the steps of 
statistical calculations and can perform assessments. Mass appraisal techniques depend upon the extent and quality of available property data. Quantitative and qualitative information can be provided only by specialists.

The method of determining the value of the land should be based on the principle "land is worth for what can be built on". Therefore, it should be based on comparability, as well as on its use conform development plans (construction intensity).

The current methodology for determining the value can be and should be used and for housing (apartments) map value.

\section{References}

[1] Glaudemans, R. J. 1999. Mass Appraisal of Real Property. Chicago: International Association of Assessing Officers.

[2] TEGoVA (The European Group of Valuers' Associations). 2012. European Valuation Standards. 7th ed. Bruxelles: TEGoVA.

[3] International Valuation Standards Committee. 2011. "IVC Framework, 2011." International Valuation Standards Committee. Accessed November 30, 2012. www.ivsc.org.

[4] IAAO (International Association of Assessing Officers). 1990. Property Appraisal and Assessment Administration. Chicago: IAAO.

[5] Council of Ministers of Republic of Albania. 2012. "For the Approval of the Methodology for Evaluating
Immovable Properties in Republic of Albania." Official Journal of the Republic of Albania 141: 7866. Accessed September 26, 2012. http://qbz.gov.al/botime/fletore_zyrt are/2012/PDF-2012/141-2012.pdf.

[6] Council of Ministers of Republic of Albania. 2014. "On Approval of the Average Cost of Residential Construction of National Housing Agency for 2014." Official Journal of the Republic of Albania 130: 5974. Accessed August 6, 2014. http://qbz.gov.al/botime/fletor e_zyrtare/2014/PDF-2014/130-2014.pdf

[7] Millington, A. F. 2000. An Introduction to Property Valuation. 5th ed. London: Estate Gazette.

[8] IVSC (International Valuation Standards Council). 2002. Exposure Draft of Proposed International Valuation Application-Mass Appraisal of Real Estate. London: IVSC.

[9] Bagdonavičius, A., and Deveikis, S. 2011. "Mass Appraisal-The Method and an Experience in Lithuania." Presented at FIG (International Federation of Surveyors) Working Week 2011 Bridging the Gap between Cultures, Marrakech, Morocco.

[10] Bagdonavičius, A., and Deveikis, S. 2005. "Individual and Mass Valuation, Present and Future Practices." Presented at FIG Working Week 2005 and GDSI-8 (Global Spatial Data Infrastructure), Cairo, Egypt.

[11] Shehu, E., and Afezolli, A. 2014. "Urban Land Value and Map of Land Values." Presented at 2nd International Conference in Architecture and Urban Design, Tirana, Albania.

[12] Castle, G. 1993. "GIS in Property Valuation: What Is It Worth?.” Business Geographics. Accessed April 8, 2015. http://www.castleconsulting.com/93gisin p.html.

[13] Thimgan, G. E. 2010. Property Assessment Valuation. 3rd ed. Kansas: IAAO, 1-8. 